Rev Med (São Paulo). 2012 jul.-set.;91(3):159-62.

\title{
Comunicação em medicina
}

\section{Communication skills in medicine}

\author{
Izabel Cristina Rios
}

Rios IC. Comunicação em medicina / Communication skills in medicine. Rev Med (São Paulo). 2012 jul.-set.;91(3):15962.

RESUMO: Comunicação efetiva e interação são competências clínicas essenciais ao profissionalismo em Medicina. Define-se comunicação efetiva como procedimento de interação do profissional da saúde e pacientes ou equipe que promove acolhimento, diálogo e entendimento recíprocos. Estudos mostram que comunicação efetiva tem impacto significativo no cuidado e aumento da qualidade da atenção à saúde. Já a falta de habilidade de comunicação está associada à má prática e erros médicos. A competência relacional e comunicacional se fundamenta em atitudes, conhecimentos e habilidades de comunicação e interação que requer ensino-aprendizagem e deve ser desenvolvida nas escolas médicas. As diretrizes curriculares do Ministério da Educação para o curso médico, desde 2001, preconizam o desenvolvimento de habilidades de comunicação. $O$ ensino-aprendizagem de comunicação deve se desenvolver ao longo da graduação de forma sistematizada, em diversos cenários de ensino, em pequenos grupos trabalhados com metodologias ativas. O processo educacional começa com objetivos educacionais básicos (introdução à conversa na prática médica) e vai se complexizando ao longo do curso médico (comunicação em cenários e situações específicos, situações difíceis e de conflito) de forma que ao seu final os alunos tenham conhecimentos, habilidades e atitudes para lidar com a maioria das situações práticas em Medicina. Na FMUSP em 2011, das 127 disciplinas da graduação, 45 tratavam de aspectos comunicacionais relativos à sua temática específica. O desafio é criar estratégia de ensino-aprendizagem voltada especificamente para o desenvolvimento de competências comunicacionais na graduação médica como um todo, tendo em vista as boas práticas em Medicina.

DESCRITORES: Comunicação em saúde; Educação médica; Humanização da assistência: Relações interpessoais.
ABSTRACT: Effective communication and interaction are essential skills clinics to professionalism in medicine. Effective communication is defined as the interaction of people that promotes acceptance, dialogue and mutual understanding. Studies show that effective communication has a significant impact on care and increases the quality of health care. However the lack of communication skills is associated with malpractice and medical errors. The relational and communicative competence is based on attitudes, knowledge and skills of communication and interaction that requires teaching and learning, and should be developed in medical schools. The curriculum guidelines of the Ministry of Education for the medical school, since 2001, point to the development of communication skills. The teaching and learning of communication should be systematically developed during the undergraduate, using various scenarios education and the work in small groups with active methodologies. The educational process begins with basic educational goals (introductory interviews in medical practice) and going to becoming more complex (communications in specific scenarios and situations, difficult situations and conflicts), so that at the end the students had knowledge, skills and attitudes to deal with the most of the situations in medical practice. In FMUSP in 2011, from 127 undergraduate disciplines, 45 of them developed communication aspects related to their specific theme. The challenge is to create teaching and learning strategy specifically to the development of communication skills in medical education as a whole, keeping in view the best practices in medicine.

KEYWORDS: Health communication; Education, medical; Humanization of assistance; Interpersonal relations. 
Comunicação efetiva e interação são hoje apontadas como competências clínicas ${ }^{1-5}$ essenciais ao profissionalismo em Medicina.

Ser capaz de desenvolver interação com o outro é condição básica para a prática médica: "A comunicação é uma habilidade clínica fundamental que pode ser ensinada e aprendida. Um médico realiza de 160000 a 300000 entrevistas durante sua vida profissional, fazendo com que a entrevista médica seja o procedimento mais comumente realizado em clínica médica" (p.624) ${ }^{1}$.

No contexto do cuidado 6 , define-se como comunicação efetiva o procedimento médico fundamentado na intersubjetividade ${ }^{7}$ compreendida aqui como resultante da interação de pessoas em um espaço relacional que promove o acolhimento, o diálogo e 0 entendimento mútuo.

No cenário internacional, as competências relacionais, que envolvem particularmente habilidades comunicacionais, empatia e construção de vínculo, têm sido amplamente estudadas por referência às suas implicações na prática médica.

Já em 1995, uma ampla revisão de literatura publicada na Social Science \& Medicine ${ }^{8}$ apresentava uma metanálise, mostrando relação positiva entre aumento da qualidade da atenção à saúde como um todo e comunicação sócio-afetiva (que inclui aspectos da subjetividade do paciente e promove vínculo), e relação negativa entre adesão e comunicação instrumental (focada nos aspectos biomédicos do adoecimento). Nesse estudo, mais precisamente aos artigos abordando pacientes com câncer e satisfação com as informações recebidas, encontrou-se que $92 \%$ dos pacientes internados queriam mais informações que as fornecidas pela equipe de saúde, $69 \%$ dos pacientes internados queriam tomar decisões sobre sua terapêutica de forma compartilhada com o médico, muito embora $71 \%$ dos médicos preferissem decidir sozinhos sobre as condutas a serem adotadas em cada caso. Observou-se também associação positiva entre informações ao paciente de forma insuficiente ou inadequada e aumento de sintomas psiquiátricos, principalmente depressão e ansiedade.

Van Dalen et al. ${ }^{9}$ da Universidade de Maastricht, em estudo que apresenta resultados de mais de vinte anos de atuação nessa temática, demonstram que a comunicação é um fator determinante em quase todos os aspectos do cuidado à saúde. A história clínica contribui em 60 a $80 \%$ dos dados para o diagnóstico. Estudos de correlação mostram associação positiva entre melhor controle de pressão arterial e glicemia, diminuição de sintomas clínicos, percepção subjetiva de saúde e boa comunicação médico paciente, no que se refere ao uso adequado do tempo de conversa, comportamento não verbal, e qualidade da informação.

Estudos de Rider e Keefer ${ }^{1}$ de Harvard mostram que a boa comunicação e relação médicopaciente têm impacto significativo no cuidado e aumento da qualidade da atenção à saúde. Já a falta de habilidade de comunicação está associada à má prática e erros médicos.

A competência relacional e comunicacional se fundamenta em atitudes, conhecimentos e habilidades de comunicação e interação que requer ensino-aprendizagem e deve ser desenvolvida nas escolas médicas, sendo um dos eixos avaliadores para a acreditação da residência médica em outros países ${ }^{10,11}$.

No ano 2003, em Harvard, líderes de escolas médicas de todo o mundo reuniram-se para discutir as competências relacionais e de comunicação que deveriam fazer parte do ensino médico curricular. $\mathrm{O}$ documento final determina que, em todas as áreas de atuação em Medicina, o médico deve ser capaz de mostrar respeito e compreensão para com pacientes, colegas e alunos, realizar escuta e argumentação que permite trocar informações, construir propostas terapêuticas e esclarecer satisfatoriamente pacientes e familiares, e saber trabalhar com membros da equipe de saúde ou grupo de outros profissionais.

As diretrizes curriculares do Ministério da Educação para o curso médico, desde 2001, preconizam o desenvolvimento de habilidades de comunicação na formação do aluno de Medicina ${ }^{12}$.

Define-se como habilidades essenciais ${ }^{2-5}$ para a comunicação médico-paciente:

1. Construir a relação médico-paciente: incentivar parceria/ promover participação ativa do paciente/ respeitar suas ideias na tomada de decisão;

2. Desenvolver a conversa: incentivar o paciente a falar sobre sua vida, saúde e tratamento/ usar perguntas abertas e fechadas adequadamente/ escutar ativamente/ usar adequadamente linguagem verbal e não-verbal (face, gestos, contato visual, posição do corpo);

3. Reunir informações: organizar conjunto completo dos dados clínico e vivencial do paciente/ estruturar, esclarecer, e resumir as informações;

4. Compreender o paciente: explorar fatores contextuais (família, cultura, idade, sexo, socioeconômico, espiritualidade, crenças, preocupações e expectativas)/ reconhecer ideias, sentimentos e valores/ perceber e respeitar limites da sua privacidade;

5. Compartilhar informações e fazer acordos: fazer acordos terapêuticos/ incentivar a participação do paciente na tomada de decisão/ considerar seus desejos, problemas e planos/ checar se ele consegue seguir o plano/ pedir outros recursos e apoio da equipe de saúde se necessário; 
6. Encerrar a conversa: verificar se o paciente tem outras questões e preocupações/ resumir e reforçar o plano de ação/ discutir o seguimento (próxima visita, o que fazer no caso de resultados inesperados, etc).

Esse conjunto técnico de habilidades essenciais em qualquer contexto da atenção à saúde só terá efetividade se ocorrer no ambiente de uma relação intersubjetiva. Não haverá comunicação efetiva se o médico apenas seguir o roteiro da consulta sem manifestar verdadeira disponibilidade interna para compreender o outro (empatia) e com ele buscar a construção de sentido para a situação de saúde em questão (cuidado).

$\mathrm{Na}$ Educação Médica, é consenso que o ensino-aprendizagem de comunicação deve se desenvolver ao longo da graduação de forma sistematizada, em diversos cenários de ensino, e preferencialmente em pequenos grupos trabalhados com metodologias ativas ${ }^{13}$. São metodologias ativas frequentemente adotadas ${ }^{3,9}$ : discussão de textos e casos em pequenos grupos, observação do aluno junto ao paciente (em tempo real), filmagem do aluno com o paciente e discussão, Medicina Narrativa (leitura e escrita), dramatização, auto-reflexão e auto-avaliação, Grupo Balint, OSCE - Objective Structured Clinical Examination, oficinas de habilidades interpessoais, aprendizagem baseada em problemas.

O processo educacional começa com objetivos educacionais mais básicos e vai se complexizando ao longo do curso médico de forma que ao final os alunos tenham conhecimentos, habilidades e atitudes conforme se descreve no Quadro 1.

Quadro 1. Objetivos educacionais do ensino-aprendizagem de comunicação em Medicina

Primeiro e segundo ano - Introdução à conversa na prática médica

1. Conhecer princípios e conceitos da comunicação na prática médica: definição de conversa, escuta atenta, linguagem, encontro, acolhimento, empatia.

2. Identificar contextos e cenários implicados na comunicação nas práticas de saúde

3. Realizar uma entrevista clínica adequada ao cuidado.

Terceiro e quarto ano - Comunicação em cenários e situações específicos

1.Conhecer princípios e conceitos da intersubjetividade: o eu e o outro, campo relacional, campo transferencial.

2. Identificar situações psicodinâmicas particulares: cuidado à criança, sexualidade, violência, conflitos, cuidado ao idoso

3. Atuar de modo empático e de acordo com a especificidade de cada encontro intersubjetivo.

Quinto e sexto ano - Comunicação em situações difíceis e de conflito

1.Demonstrar conhecimentos sobre: intersubjetividade, técnicas comunicacionais, empatia, psicodinâmica de situações específicas

2.Demonstrar habilidades comunicacionais para lidar com situações de dificuldades específicas (por ex. violência, conflitos, más noticias, emergência e urgência, paciente psiquiátrico, etc.)

Na FMUSP em 2011, das 127 disciplinas da graduação, 45 (duas do campo das humanidades médicas e as demais predominantemente da área clínica) tratavam de aspectos comunicacionais relativos à sua temática específica. Nosso desafio é criar estratégia de ensino-aprendizagem ou de gestão do conhecimento voltado especificamente para o desenvolvimento de competências comunicacionais na graduação médica como um todo, temática reconhecidamente importante para as boas práticas em Medicina.

Agradecimentos: Ademir Lopes Junior, Denise Ballester, Silmar Gannam, Diógenes Batista da Silva, Ana Cláudia Camargo, Dulce Maria Senna e Milena Gros, que significativamente contribuíram nas discussões sobre esse tema e na elaboração dos objetivos educacionais apresentados neste artigo. 


\section{REFERÊNCIAS}

1. Rider EA, Keefer $\mathrm{CH}$. Communication skills competencies: definitions and a teaching toolbox. Med Educ. 2006;40:624-9.

2. Makoul G. Communication skills education in medical school and beyond. JAMA. 2003;289(1):93.

3. Makoul G. A guide for instructor and learners for teaching and assessing communication skills. The SEGUE framework. Program in Communication \& Medicine. Chicago, III.: Northwestern University Feinberg School of Medicine; 2005. Available from: http://www.pcm. northwestern.edu

4. Kurtz SM, Silverman JD, Draper J. Calgary - Cambridge guide to the medical interview - communication process. Oxford: Radcliffe Medical Press; 1998.

5. Kurtz SM, Silverman JD, Benson J, Draper J. Marrying content and process in clinical method teaching: enhancing the Calgary-Cambridge guides. Acad Med. 2003;78(8):802-9.

6. Ayres JRM. Cuidado e reconstrução das práticas de saúde. Interface Educ Comun Saúde. 2004;8(14):7392.

7. Coelho JrNE, Figueiredo LC. Figuras da intersubjetividade na constituição subjetiva: dimensões da alteridade.
Interações. 2004;9(17):9-28.

8. Ong LML, Haes JCJM, Hoos AM, Hoos LFB. Doctorpatient communication: a review of the literature. Social Sci Med. 1995;40(7):903-18.

9. Van Dalen J, Bartholomeus P, Kerkhofs E, Lulofs R, Van Thiel J, Rethans JJ, Scherpbier AJ, Van Der Vleuten CP. Teaching and assessing communication skills in Maastricht: the first twenty years. Med Teach. 2001;23(3):245-51.

10. Association of American Medical Colleges. Medical school objectives. 2005. Available from: http//www. aamc.org/meded/msop/msop1.pdf.

11. Accreditation Council for Graduate Medical Education ACGME, 2007. Available from: http://www.acgme.org/ acWebsite/home/home.asp

12. Brasil. Diretrizes Curriculares do Curso de Medicina. Brasília; 2004 [citado 20 jul. 2012]. Disponível em: http:// portal.mec.gov.br/cne/arquivos/pdf/CES04.pdf.

13. Rios IC. Subjetividade contemporânea na educação médica: a formação humanística em medicina [Tese]. São Paulo: Universidade de São Paulo, Faculdade de Medicina; 2010. 